\title{
DESARROLLO Y ESTABILIDAD DE PRECIOS EN MÉXICO
}

\author{
ARIEL BUIRA* \\ El Colegio de México
}

\section{INTRODUCCIÓN}

Uno de los problemas más debatidos por los economistas del desarrollo en el decenio pasado ha sido el énfasis que debe atribuirse al exceso de demanda y a los factores estructurales en el proceso de inflación experimentado por los países de América Latina. Los problemas teóricos implícitos han sido discutidos extensamente $\mathrm{y}$, aunque mucho se ha aprendido, no parece probable que de esta manera se llegue a un acuerdo entre los economistas sobre una explicación general, válida para todos los países. Parece haber lugar para el estudio de las experiencias de algunos países con el propósito de determinar cuáles fueron las influencias dominantes sobre los cambios en el nivel general de los precios.

El caso mexicano tiene interés particular porque el crecimiento de México es sobresaliente, y sus experiencias inflacionarias, aunque considerables, son más moderadas que aquellas de cualquier otro país importante del área. El propósito de este trabajo es revisar la experiencia inflacionaria de la economía mexicana en el período de posguerra (1945-1966) e investigar las causas de los incrementos de los precios.

Este estudio se divide en tres partes: la primera considerará las principales influencias sobre el nivel de la demanda y la política monetaria que se siguió para regularla. La segunda buscará determinar los efectos de los costos de la mano de obra sobre los precios y la formación de capital. La tercera investigará si la oferta insuficiente de alimentos o de divisas constituyeron una fuente de presión sobre el nivel de los precios.

\section{INFLUJo dE LA DEMANDA Y POLÍtrCa MONETARIA}

Por conveniencia dividiremos el período de estudio en dos de igual extensión: los años de 1945 a 1956 en los cuales los precios se incrementaron a una tasa media de $9 \%$ anual y los años posteriores durante los cuales los precios se han elevado a razón de 3\% anual.

El período de inflación puede ser caracterizado como aquel en que

* El autor agradece a Víctor L. Urquidi, Carlos Tello y Donald Keesing sus valiosos comentarios. Este trabajo se escribió originalmente para la revista Weltwirtschaftliches Archiv, de la Universidad de Kiel, República Federal de Alemania, donde apareció en el Vol. 101, Núm. 1, septiembre de 1968. 
las variaciones a corto plazo en las exportaciones fueron la determinante principal del nivel del ingreso nacional y el empleo en México. La magnitud del ingreso generado por el sector de exportaciones como proporción del ingreso nacional fue similar a aquella representada por la formación bruta de capital, pero las exportaciones fueron la influencia autónoma dominante en la determinación del nivel del ingreso y de la inversión. Tres ciclos notables en el nivel de demanda de este período dominan la tasa de crecimiento económico y la tasa de cambio del nivel de precios.

Por otra parte, el decenio de estabilidad, 1956-1966, comienza con un estancamiento de las exportaciones que se prolonga hasta 1961, fecha en la que la inversión pública tuvo que convertirse en la influencia autónoma principal sobre el nivel de demanda y del ingreso. Cuando las exportaciones aumentaron nuevamente en 1961, México se encontraba en el centro de una situación política difícil (la crisis cubana) y la inversión privada no respondió al estímulo del sector externo ni se recobró totalmente sino hasta 1963. En 1964, último año de la administración del presidente López Mateos, hubo un incremento agudo en la construcción de obras públicas y una aceleración de obras iniciadas que debían terminarse antes del fin del año. Esta circunstancia, conjuntamente con cosechas excepcionales y una alta inversión privada, produjo ese año un crecimiento del $10 \%$ en términos reales. Durante el decenio de estabilidad se observó un incremento considerable de la deuda pública externa, el cual contribuyó al financiamiento de las importaciones durante los años de estancamiento de las exportaciones $\mathrm{y}$ al financiamiento de la inversión pública durante la primera parte de los años 60 .

\section{El periado de inflación}

La posguerra (1945-1949). Como resultado de los superávit de la balanza comercial y el influjo de capitales, por una parte, y del déficit presupuestario, por otra, la oferta monetaria se triplicó entre 1941 y 1945. Una parte de esta enorme expansión monetaria se retuvo en saldos líquidos para financiar la compra de bienes difíciles de obtener durante la guerra. A medida que las materias primas y el equipo de capital volvieron gradualmente a los mercados, este poder de compra acumulado empezó a utilizarse. La demanda postergada se volcó sobre el sector externo provocando un aumento rápido de las exportaciones y del nivel de los precios, mientras las exportaciones y las reservas de divisas disminuían. Las condiciones externas tuvieron un efecto deflacionario hasta 1948, dando lugar a una pequeña reducción de la oferta monetaria.

El crecimiento del producto bruto fue inferior al de la población en 1947 y el déficit comercial no respondió al incremento de los aranceles a las importaciones de diciembre de ese año. En esta forma, después de agotar las reservas monetarias, los créditos a corto plazo del Fondo Monetario Internacional y los créditos de Estados Unidos, se permitió que el tipo de cambio fluctuara libremente en el mercado durante un año y se fijó la nueva paridad en junio de 1949 a 8.65 pesos por dólar, lo que constituyó una devaluación de $44 \%$. 
Un aumento sustancial del nivel de precios entre el final de la guerra y la devaluación debe atribuirse a una aceleración de la velocidad de circulación de la oferta monetaria existente como consecuencia del proceso de intentar satisfacer la demanda postergada durante la guerra.1

La guerra de Corea: expansión y receso. La devaluación y la recuperación de la economía de los Estados Unidos al iniciarse la guerra de Corea dieron lugar a que la economía mexicana experimentara una expansión rápida de sus exportaciones. La gran demanda externa de los años 1950-1951 ocasionó las mayores presiones inflacionarias sufridas desde 1945.

A medida que las exportaciones se redujeron, el déficit presupuestario incrementó la demanda global lo suficiente para mantener el nivel del PNB pero no para impedir la disminución del ingreso per capita. El año de 1952, con su estabilidad de precios, aparece como un período de transición hacia el receso que siguió.

El descenso de la actividad económica en Estados Unidos en 1953 provocó una reducción del $20 \%$ en el volumen de las exportaciones mexicanas y del $16 \%$ en la relación de precios del intercambio. A pesar del crecimiento rápido de la población, el nivel del consumo total fue semejante al del año precedente y las perspectivas parecían tan inciertas que la inversión disminuyó por el segundo año consecutivo. Los esfuerzos gubernamentales para estimular la economía mediante una política monetaria expansionista y un presupuesto deficitario tuvieron poco éxito. La demanda no se recobró, los precios bajaron por primera vez desde 1940 y el ingreso per capita sufrió una reducción del $2 \%$.

Mediados del decenio de los 50: 1954-1956. Si bien por las politicas expansionistas de 1953 se inició la recuperación a partir de los primeros meses de 1954, las reservas de divisas cayeron tanto como lo hicieron en los dos años previos, y a pesar de un aumento de $25 \%$ de los impuestos a la importación el déficit de la balanza de pagos resultó alarmante. Para evitar una nueva disminución de las reservas de oro y divisas, el peso fue devaluado nuevamente. La nueva paridad se fijo en $\$ 12.50$ por dólar en abril de 1954 , una reducción de $30 \%$ respecto a su tipo previo. ${ }^{2}$

El impacto psicológico de la devaluación fue considerable en la mayoría de los mexicanos, ${ }^{3}$ y la confianza en el peso y en las políticas

1 La velocidad-ingreso de circulación experimentó un incremento de $\left(\frac{8.0-5.5}{5.5}=.455\right) 46 \%$ entre 1945 y 1947. La mayor velocidad compensó la reducción de 100 millones en el medio circulante, siendo la diferencia equivalente a un incremento neto del $43 \%$ en la oferta monetaria en un período de dos años.

2 EI Banco de México se aprovechó de los beneficios surgidos de las tenencias de dólares de los bancos comerciales. Los bancos fueron compensados de acuerdo con el tipo de cambio anterior por sus existencias en dólares en vísperas de la devaluación. Aproximadamente 300 millones de pesos fueron así absorbidos, y se evitó una expansión del $10 \%$ de la oferta monetaria.

3 Fue tan grande el impacto que por muchos años al acercarse la Semana Santa (la época de devaluación en 1954) se efectuaban cambios de pesos a dólares. 
económicas del gobierno se redujo. ${ }^{4}$ Como se pensaba que las reservas de divisas eran suficientes, la devaluación no sólo fue una gran sorpresa sino que fue considerada como innecesaria o excesiva. Desde 1954, el tipo de cambio ha sido más que una relación entre monedas y se ha convertido en un símbolo de la estabilidad de la nación.

Las políticas fiscal y monetaria de índole expansionista que se implantaron en 1953 iniciaron una recuperación a la que ayudó un resurgimiento de las exportaciones mexicanas como consecuencia de la recuperación de la economía norteamericana. Tal vez fue éste el factor determinante, y no la devaluación, ya que las importaciones continuaron aumentando en 1954-1955 mientras que la oferta de bienes exportables, especialmente productos agrícolas, fue inelástica a corto plazo.

Después de más de un decenio de precios en alza, las presiones sociales llevaron al gobierno a declarar en 1952 que el logro de la estabilidad de precios era uno de sus principales objetivos. Sin embargo, la devaluación imposibilitó la estabilidad y en 1954-1955 los precios volvieron a elevarse en forma considerable. Después de esto, el gobierno pareció más que nunca decidido a restringir al alza de los precios aun a riesgo de reducir la tasa de crecimiento.

\section{El comienzo de la èstabilidad}

Últimos años del decenio de los 50. De 1957 al fin del decenio, México gozó de un período de relativa estabilidad de precios al aumentar éstos entre 4 y $7 \%$ anualmente mientras el crecimiento del ingreso se reducía. Las exportaciones se estancaron alrededor de su nivel de 1955, notándose la ausencia de las bruscas fluctuaciones de años anteriores. La inversión privada también se estancó durante 1957-1960 pero aumentó ligeramente en 1960. Este estancamiento se compensó por un aumento de la inversión pública, al declarar el gobierno que no estaba dispuesto a permitir que el desarrollo del país se frenara por falta de inversión privada. La aceleración de la reforma agraria y la nacionalización de las restantes empresas eléctricas, aunadas a la política externa seguida con relación a Cuba, parecen haber dado a los inversionistas privados la idea de que la política viraba hacia la izquierda, lo que los volvió reticentes a aumentar su inversión. ${ }^{5}$

La expansión de la oferta monetaria continuó a una tasa media de $9 \%$ anual, a pesar del leve efecto contraccionista de la disminución de la reserva de divisas, lo que facilitó el control de aquélla. La principal fuente de mayor liquidez fue la creación de crédito por el sistema bancario. El crédito fue escaso durante la mayor parte del decenio en respuesta a controles del Banco de México destinados a mantener moderados los incrementos de los precios.

Las exportaciones, en su mayor parte ligadas al mercado norteamericano, habían sido el elemento dinámico autónomo de la deter-

4 Se creyó que el gobierno no hizo lo posible por mantener la tasa de cambio puesto que no recurrió a un crédito del Fondo Monetario Internacional.

5 Probablemente la caída de la inversión privada se debió a la existencia de capacidad excesiva en la industria mexicana. Esta hipótesis sería compatible con el fuerte incremento de la producción en 1963-1964. 
minación del nivel de demanda en todo el período desde 1945. Sin embargo, en la segunda mitad del decenio, al perder las exportaciones su papel dinámico, la inversión surgió como la principal influencia sobre el nivel de la demanda y el ingreso.

De 1961 en adelante. De 1961 a 1965, la expansión y el receso fueron el resultado de factores políticos. La crisis cubana indujo una pérdida de confianza que dio lugar a una disminución de la inversión privada y a una fuga de capitales. Sólo una muy decidida política de inversión pública evitó que cayera el crecimiento del PNB por debajo del de la población. A pesar de la notable recuperación de las exportaciones en 1961, la confianza se recobró muy lentamente, y la inversión privada y las importaciones de 1962 permanecieron al nivel de los dos años previos. Los aumentos de la inversión pública fueron financiados parcialmente mediante endeudamiento externo y por venta de bonos al sistema bancario. La deuda pública se duplicó entre 1955 y 1960 y se volvió a duplicar entre 1960 y 1964. (Véase el cuadro 1.)

\section{Cuadro 1}

México: Crecimiento de LA DEUda EXTERna Y DEL MERCado DE VALORES DE RENTA FIJA, 1955-1966

\begin{tabular}{|c|c|c|c|c|}
\hline \multirow[t]{2}{*}{ Año } & \multirow{2}{*}{$\begin{array}{l}\text { Deuda externa } \\
\text { (millones de } \\
\text {. dólares) }\end{array}$} & \multirow{2}{*}{$\begin{array}{l}\text { Valor de los valo- } \\
\text { res de renta fija } \\
\text { en poder del siste } \\
\text { ma bancario } \\
\text { (millones de pesos) }\end{array}$} & \multicolumn{2}{|c|}{$\begin{array}{c}\text { Crecimiento anual } \\
\left(\phi_{0}\right)\end{array}$} \\
\hline & & & $\begin{array}{l}\text { Deuda } \\
\text { externa }\end{array}$ & $\begin{array}{l}\text { Tenencias } \\
\text { de valores }\end{array}$ \\
\hline $\begin{array}{l}1955 \\
1959 \\
1960 \\
1961 \\
1962 \\
1963 \\
1964 \\
1965 \\
1966\end{array}$ & 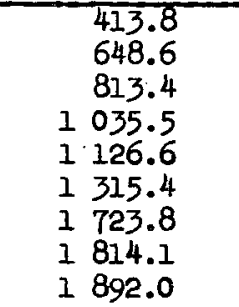 & $\begin{array}{rr}9 & 165 \\
14 & 655 \\
17 & 889 \\
19 & 838 \\
22 & 106 \\
25 & 720 \\
35 & 752 \\
53 & 014 \\
68 & 596\end{array}$ & $\begin{array}{l}14^{*} \\
25 \\
33 \\
4 \\
17 \\
31 \\
5 \\
4\end{array}$ & $\begin{array}{l}12.5^{*} \\
22 \\
11 \\
11.4 \\
16.3 \\
38.6 \\
48.3 \\
29.4\end{array}$ \\
\hline
\end{tabular}

Fuente: Banco de México, informes anuales.

* Promedio 1955-1959.

No fue sino hasta 1963 cuando la recuperación fue total. Aumentaron tanto la inversión pública como la privada. Hubo un ingreso sustancial de capital extranjero, lo que, aunado a una política monetaria expansionista, se tradujo en una tasa de crecimiento del PNB de más del $6 \%$. Los precios permanecieron estables: aumentaron menos del $1 \%$ al absorber las empresas y los individuos una gran parte de la expansión del circulante con objeto de restaurar sus niveles previos de liquidez.

En 1964, las buenas cosechas, el aumento de $9 \%$ de las exporta. ciones y de $5 \%$ de la inversión privada hubieran bastado para que se 
alcanzara una buena tasa de crecimiento. Fue también el último año del sexenio del presidente López Mateos, por lo que la que la inversión pública se elevó en un intento de terminar todas las obras de construcción. El aumento real del PNB fue de $10 \%$, el mayor desde la devaluación de 1954. A pesar de un endeudamiento externo neto adicional de 384 millones de dólares y de la emisión de 60 millones de dólares de bonos gubernamentales en los mercados extranjeros de capital para financiar la inversión pública (lo que conjuntamente representó más del $40 \%$ del valor de la exportación) y de la absorción de bonos gubernamentales por el público, se presentaron presiones inflacionarias moderadas.

Durante 1965 y 1966 las exportaciones continuaron creciendo más del $8 \%$ anualmente. La inversión privada se mantuvo elevada en ambos años, pero la inversión pública en 1965 cayó por abajo de los niveles de 1964 al tener que establecer el régimen del presidente Díaz Ordaz sus propias prioridades. La oferta de dinero creció durante estos años a una tasa media anual del $10 \%$, sólo $4 \%$ mayor que el crecimiento del PNB, con lo que se logró estabilidad de precios.

La expansión de los pasivos bancarios, aunada a la estabilidad de los precios desde el fin del decenio anterior, favoreció un crecimiento extraordinario del mercado de bonos gubernamentales y de otros valores de renta fija. (Véase el cuadro 1.) A su vez, esto permitió al sistema bancario volverse un mecanismo más eficiente para la transferencia de ahorros de los sectores superavitarios a los deficitarios. El elevado encaje bancario forzó al sistema a mantener una proporción de sus reservas en bonos gubernamentales, alimentándose así el déficit del sector público con recursos financieros sin recurrir a la expansión monetaria con sus efectos inflacionarios.

\section{Politica monetaria.}

Los instrumentos de control. El principal instrumento de política monetaria en México, sobre el cual se ha depositado una confianza casi absoluta, ha sido la variación de los niveles del encaje bancario. Aunque el Banco de México ha establecido a menudo requisitos muy elevados de reserva a los bancos comerciales, también ha permitido a éstos mantener el $85 \%$ de las reservas en bonos gubernamentales, valores industriales y en la forma de créditos a ciertos sectores autorizados por las autoridades monetarias. ${ }^{6}$

En la determinación de las tenencias de activos de las instituciones financieras privadas las autoridades parecen tener la siguiente escala de prioridades: 1) las necesidades del gobierno federal; 2) aquellas de otros organismos públicos ; 3) el uso "productivo" de fondos por el sector privado. $\mathrm{Y}$ es el sector privado, en la medida en que su uso de fondos sea considerado socialmente improductivo o especulativo, el que lleva el peso del control.

En la práctica, los requisitos generales de reserva han sido usados

6 Para un mejor conocimiento del sistema y su operación véase Mario Ramón Beteta, "El banco central: instrumento del desarrollo económico de México", en Tres aspectos del desarrollo económico de México, México, Publicaciones Especializadas, S. A., Colección SELA, Vol. 8, 1963, pp. 75-133. 
para mantener la estabilidad, pero a través de los requisitos de reserva se opera un control selectivo de crédito, utilizándose la reserva en efectivo para garantizar la liquidez del sistema bancario. Sin embargo, al permitir a los bancos la inversión de la mayor parte de sus reservas se reduce sensiblemente la efectividad de las variaciones en los requisitos de reserva como una medida antiinflacionaria, en particular debido a que en períodos de demanda excedente todo crédito adicional a actividades productivas es inflacionario.

El poder de la política monetaria como fuerza estabilizadora se vio debilitado por el crecimiento de las financieras que estuvieron, hasta 1957, libres de los controles impuestos a los bancos comerciales. Las financieras tienen dos funciones básicas: promueven empresas y llevan a cabo intermediación a mediano y a largo plazo. Desde 1950, las financieras han estado autorizadas para prestar a empresas y a individuos a corto plazo, recibir fondos y emitir valores. En años recientes, el financiamiento total de las financieras ha sido en ocasiones, en cifras absolutas y relativas, mayor que el otorgado por los bancos de depósito. ${ }^{7}$ Las financieras participan en el $40 \%$, más o menos, del pasivo total del sistema bancario privado y el financiamiento total por ellas otorgado es el $48 \%$ del financiamiento total de fuentes privadas.

El control de la demanda. A lo largo del período, la expansión de la oferta monetaria ha sido mayor que la requerida por el crecimiento del producto en términos reales. Esta expansión ha constituido una fuerza inflacionaria que parecería ${ }^{8}$ explicar una parte sustancial del aumento de los precios. (Véase el cuadro 2.)

Aunque la expansión interna total de la oferta monetaria fue más de dos veces mayor que la causada por factores externos, los períodos en que la demanda excedente fue mayor fueron de cuantiosos excedentes de balanza de pagos y en consecuencia fue entonces cuando se presentaron los incrementos más grandes de precios, por ejemplo, en 1950 y $1955 .^{\circ}$

El permitir la inversión parcial de las reservas legales de los bancos y el dejar a las financieras fuera del alcance de los controles del banco central fueron excepciones a las restricciones que a menudo limitaron la efectividad de la política monetaria. El que hayan sido bastante obvias parece indicar una cierta renuencia de las autoridades

7 Ibid., p. 116. Véase también D. Brothers y L. Solís, Evolución financiera de México, México, CEMLA, 1967.

8 Harberger sugiere, como un tema sobre el cual hay acuerdo general, que en una economia que está creciendo a la tasa de $3 \%$ anual, un incremento de la oferta monetaria del 4 o el $5 \%$ anual no es inflacionario. Más allá de esto, "el efecto último de un incremento adicional del $1 \%$ en la oferta monetaria es un incremento adicional de aproximadamente $1 \%$ en todas las categorías de precios". Por lo tanto, un incremento de la oferta monetaria de hasta el $4 \%$ en exceso de la tasa de crecimiento del producto bruto del $6 \%$ anual será probablemente absorbido sin ninguna elevación del nivel de precios. A. C. Harberger, en W. Baer e I. Kerstenetzky, compiladores, Inflation and Growth in Latin America, Homewood, Ill., Irwin, 1964, p. 333.

9 Una excepción parecen ser los años inmediatos de postguerra, 1946-1947; pero entonces los superávit de la balanza de pagos de los años de guerra permitieron a la economía la liquidez tan elevada que contribuyó a los incrementos de los precios. 
Cuadro 2

MÉXICO: CAMBIOS MONETARIOS Y PRECIOS, 1939-1966

\begin{tabular}{|c|c|c|c|c|c|c|}
\hline & \multirow{2}{*}{$\begin{array}{l}\text { Producto na- } \\
\text { clonal bruto } \\
\text { (miles de mi } \\
\text { llones de pe } \\
\text { sos de 1950) }\end{array}$} & \multirow{2}{*}{$\begin{array}{l}\text { Indice de } \\
\text { precios al } \\
\text { mayoreo } \\
(1954=100)\end{array}$} & \multirow{2}{*}{$\begin{array}{l}\text { Oferta de } \\
\text { dinero } \\
\text { (miles de } \\
\text { millones } \\
\text { de pesos) }\end{array}$} & \multicolumn{3}{|c|}{ Camolos porcentuales en } \\
\hline & & & & $\begin{array}{c}\text { PNB de } \\
1950\end{array}$ & $\begin{array}{l}\text { Oferta } \\
\text { de dine- } \\
\text { ro }\end{array}$ & $\begin{array}{l}\text { Nivel de } \\
\text { precios }\end{array}$ \\
\hline $\begin{array}{l}1939 \\
1940 \\
1941 \\
1942 \\
1943 \\
1944 \\
1945 \\
1946 \\
1947 \\
1948 \\
1949 \\
1950 \\
1951 \\
1952 \\
1953 \\
1954 \\
1955 \\
1956 \\
1957 \\
1958 \\
1959 \\
1960 \\
1961 \\
1962 \\
1963 \\
1964 \\
1965 \\
1966\end{array}$ & $\begin{array}{r}32.0 \\
34.1 \\
34.5 \\
36.1 \\
37.6 \\
40.6 \\
43.6 \\
45.4 \\
45.6 \\
50.4 \\
54.8 \\
58.2 \\
62.7 \\
66.2 \\
68.1 \\
73.5 \\
76.0 \\
79.7 \\
84.7 \\
93.2 \\
98.2 \\
105.6\end{array}$ & $\begin{array}{l}46.3 \\
53.3 \\
56.4 \\
60.5 \\
66.3 \\
72.5 \\
89.9 \\
93.2 \\
91.4 \\
100.0 \\
113.6 \\
118.9 \\
124.0 \\
129.5 \\
131.0 \\
137.5 \\
138.8 \\
141.3 \\
142.1 \\
143.1 \\
150.9\end{array}$ & $\begin{array}{r}3.59 \\
3.51 \\
3.49 \\
3.99 \\
4.46 \\
6.12 \\
8.80 \\
7.08 \\
7.65 \\
8.70 \\
10.52 \\
11.69 \\
12.49 \\
13.39 \\
15.43 \\
16.89 \\
18.01 \\
20.27 \\
23.52 \\
27.44 \\
29.52 \\
32.75\end{array}$ & $\begin{array}{r}1.0 \\
\text { prom. } \\
9.1 \\
9.1 \\
6.6 \\
1.2 \\
4.6 \\
4.2 \\
8.0 \\
7.4 \\
1.4 \\
0.4 \\
10.5 \\
8.7 \\
6.2 \\
7.7 \\
5.6 \\
2.9 \\
5.7 \\
3.5 \\
4.8 \\
6.3 \\
10.0 \\
5.4 \\
7.0\end{array}$ & $\begin{array}{r}20.7 \\
\text { prom. } \\
26.5 \\
6.5 \\
-2.2 \\
10.6 \\
14.3 \\
11.8 \\
37.2 \\
11.1 \\
4.1 \\
8.1 \\
13.7 \\
20.0 \\
11.1 \\
6.8 \\
7.2 \\
15.2 \\
9.5 \\
6.6 \\
12.6 \\
16.8 \\
16.6 \\
6.8 \\
11.4\end{array}$ & $\begin{array}{r}6.3 \\
\text { prom. } \\
12.7 \\
\\
12.7 \\
19.5 \\
9.7 \\
4.6 \\
6.4 \\
7.0 \\
20.0 \\
3.2 \\
-1.0 \\
10.8 \\
12.6 \\
7.1 \\
6.7 \\
5.5 \\
4.1 \\
4.8 \\
0.9 \\
1.8 \\
0.6 \\
4.2 \\
1.9 \\
2.9\end{array}$ \\
\hline
\end{tabular}

Fuente: Banco de México, informes anuales.

monetarias a llevar a la práctica las restricciones en toda su extensión.

Buscando la estabilidad se ha usado insuficientemente el potencial de la política fiscal. Ésta, sin embargo, parece estar dominada por el ciclo político sexenal y no se altera para tomar en cuenta el nivel de la demanda. A lo largo de un período de 21 años, cuya mejor descripción es que fue uno de elevada demanda global, se incurrió en déficit presupuestales en 16 años. En los años de mayor demanda externa, se lograron superávit pero no de magnitud suficiente para absorber más de una pequeña parte del excedente.

En años recientes, al recurrir el gobierno a los créditos externos y al crecer el mercado de bonos se dependió menos de la creación interna de crédito, disminuyó la participación del crédito de los bancos comerciales absorbido por el gobierno y al finalizar el período la participación del gobierno federal había caído hasta el $15 \%$, o sea 
la mitad de lo que fue en 1945. Por lo tanto, la mayor parte del crédito otorgado por los bancos comerciales (entre 70 y $85 \%$ ) ha sido absorbido por el sector privado de la economía, principalmente por la industria, seguida por el comercio y la agricultura.

Las importantes y crecientes demandas de crédito del sector privado pueden deberse a una escasez de capital de trabajo. Durante la mayor parte del período los negocios se han expandido a una tasa más acelerada que la permitida por los recursos propios de capital y por esta razón han tenido que depender cada vez más del crédito comercial y del bancario. Esta situación podrá entenderse mejor pensando en factores institucionales tales como el tamaño muy limitado del mercado de nuevas emisiones hacia el que las empresas podrían recurrir en búsqueda de capital y la renuencia e ignorancia de muchos individuos que han obstaculizado el que se recurra a él.

Una vez que comienza el proceso inflacionario de creación de crédito, la elevada demanda de bienes y servicios impulsará a los precios hacia arriba y el proceso puede volverse autosostenido, a menos que se adopte una política monetaria restrictiva. ¿Puede concluirse que México se enfrenta a una inflación de crédito? El hecho de que la oferta monetaria ha estado aumentando más rápidamente que el producto no es evidencia de que se presente una inflación por exceso de demanda - que el aumento de la oferta monetaria sea causa del alza de los precios. La expansión crediticia puede deberse a la necesidad de financiar incrementos autónomos de los costos, y una inflación de costos puede financiarse aumentando la oferta de crédito.

Si los costos de los insumos han estado aumentando durante un período dado, las empresas requerirán mayor cantidad de capital de trabajo que antes para poder absorber los costos de producción más elevados, y si el alza de costos es de tipo general, los costos más altos implicarán que se necesite más crédito. La inflación de costos no puede continuar por mucho tiempo si las autoridades fiscal y monetaria no permiten un aumento continuo de la oferta de dinero, pero esto se asociaría con menor nivel de empleo y de producto y retrasaría el crecimiento de la economía. Las autoridades monetarias pueden considerar que ya que hay "una asimetría entre los costos sociales de permitir presiones inflacionarias de $X \%$ al año y los costos sociales de una deflación de $X \%$ al año, es obvio que la política pública no debe obedecer el supuesto de que lo uno es tan malo como lo otro".10

Los objetivos fundamentales de la política económica del gobierno de México fueron, como se ha señalado, el logro del crecimiento económico y el mantenimiento del poder adquisitivo de la moneda. Sin embargo, estos objetivos pueden en cierto grado ser incompatibles entre sí, por lo que el gobierno ha fijado como meta "una tasa razonable de crecimiento con una inflación 'moderada'". Parece ser que el énfasis ha fluctuado de crecimiento a estabilidad en períodos de aumentos rápidos de los precios y de estabilidad a crecimiento cuando la actividad económica ha estado a niveles bajos. A lo largo de la mayor parte del período la expansión de la oferta monetaria fue mayor que la requerida por el crecimiento del producto en términos reales. A esta

10 A. C. Harberger, loc. cit. 
política debe considerársele responsable de los aumentos de precios que ocurrieron, a no ser que pueda demostrarse que las autoridades monetarias actuaron en respuesta a aumentos autónomos de precios tales como costos crecientes de la mano de obra o aquellos atribuibles a desequilibrios estructurales. En las páginas siguientes se tratará de determinar si dichos aumentos autónomos de costos se presentaron.

\section{II. ¿INFLACIÓN DE COSTOS O AHORRO FORZADO?}

Las teorías de la inflación de costos indican que puede presentarse un aumento de salarios habiendo o no demanda excedente en el mercado de trabajo, y que cualquier aumento en los salarios se traslada vía aumentos de los precios de los bienes de uso final. El proceso se vuelve autosostenido si este aumento de precios conduce a otro aumento de salarios. En ausencia de cambios en la oferta de dinero o de su velocidad de circulación, tales aumentos de salarios y de precios conducirán al desempleo.

\section{Salarios, productividad y costos de la mano de obra}

Un examen del comportamiento de los salarios desde 1940 muestra que los salarios nominales (medidos por el salario mínimo urbano) han aumentado considerablemente, pero que el costo de la vida ha aumentado aun más. Los salarios reales en 1960 estaban muy por debajo de su nivel de 1940, aunque eran superiores a los de 1950. (Véa-

\section{Cuadro 3}

MÉxico: Salarios y costos de la Mano de OBRA, 1940-1965

\begin{tabular}{|c|c|c|c|c|c|c|}
\hline Aี̃o. & $\begin{array}{l}\text { Costo de } \\
\text { la vida } a /\end{array}$ & $\begin{array}{r}\text { Salarios } \\
\text { nomina- } \\
\text { Ies b }\end{array}$ & $\begin{array}{l}\text { Indice de } \\
\text { salarios } \\
\text { reales }\end{array}$ & $\begin{array}{l}\text { Producto me } \\
\text { dio por per } \\
\text { sone emplea } \\
\text { da en la in } \\
\text { dustria y } \\
\text { en los ser- } \\
\text { vicios } \\
\text { (pesos de } \\
1950 \text { ) }\end{array}$ & $\begin{array}{l}\text { Indice } \\
\text { de } \\
\text { "produc } \\
\text { tivi- } \\
\text { dad" }\end{array}$ & $\begin{array}{l}\text { Indice } \\
\text { de cos } \\
\text { to de } \\
\text { la mano } \\
\text { de obra } \\
\text { por uni } \\
\text { dad de } \\
\text { produc- } \\
\text { ción }\end{array}$ \\
\hline 1940 & 21.3 & 1.52 & 100.0 & 7850 & 100 & 100 \\
\hline $\begin{array}{l}1945 \\
1950 \\
1955 \\
1960 \\
1965\end{array}$ & $\begin{array}{r}45.1 \\
75.3 \\
116.0 \\
154.2 \\
169.1\end{array}$ & $\begin{array}{r}1.90 \\
3.35 \\
6.34 \\
9.89 \\
16.00\end{array}$ & $\begin{array}{r}59.2 \\
62.3 \\
76.7 \\
89.5 \\
132.0\end{array}$ & $\begin{array}{r}9295 \\
11600 \\
12500\end{array}$ & $\begin{array}{l}118 \\
148 \\
159\end{array}$ & $\begin{array}{l}51 \\
60.5 \\
83\end{array}$ \\
\hline
\end{tabular}

Fuente: Nacional Financiera, La economia mexicana en cifras, México, 1966.

- Éste es un índice del costo de la vida obrera en la ciudad de México, preparado por la Dirección General de Estadística, y está sujeto a importantes salvedades.

b Promedio no ponderado del salario mínimo urbano en 111 regiones económicas en que el país se ha dividido. Fuente: Comisión Nacional de los Salarios Mínimos. 
se el cuadro 3.) Esto no debe extrañar en vista de la abundancia de mano de obra y de la debilidad de los sindicatos.11 Por otra parte, un aumento sostenido de la productividad (medida como producto total por persona empleada) mientras los salarios reales disminuían, tuvo el efecto de reducir los costos de la mano de obra por debajo de los prevalecientes en 1940. Esto significa que los empresarios habrían podido absorber aumentos sustanciales de los salarios sin que aumentaran los costos de la mano de obra por unidad de producción.

Los salarios reales en el sector manufacturero cayeron por abajo de su nivel de 1945 en los años de la posguerra y recuperaron sus niveles de 1945 sólo en 1955, según una estimación, y en 1960, según otra. No hay, por desgracia, estimaciones satisfactorias de los aumentos de la productividad en las industrias manufactureras, pero puede suponerse que el aumento promedio de la productividad que se ha estimado para toda la economía es aplicable al sector manufacturero. Esta puede ser una subestimación, ya que la productividad en el sector considerado aumenta más rápidamente que en la mayoría de los otros sectores. Además, un cálculo del valor agregado por hora-hombre habría sido más adecuado y probablemente habría mostrado un aumento más rápido. En cualquier caso, el resultado de que hubiese salarios reales menores o, en el mejor de los casos, constantes, y productividad más elevada fue la reducción sustancial (de 25 a $40 \%$ ) de los costos de la mano de obra por unidad de producción durante el período. (Véase el cuadro 4.)

\section{Cuadro 4}

México: Costo DE la MaNo DE OBRa EN LA INDUStria DE TRANSFORMACIÓN, 1945-1960

\begin{tabular}{|c|c|c|c|c|c|}
\hline Año & $\begin{array}{c}\text { Costo } \\
\text { de } 1 a \\
v 1 d a \\
a / \\
(1945=100)\end{array}$ & $\begin{array}{l}\text { Indice de sa } \\
\text { larios medios } \\
\text { en la Indus- } \\
\text { tria de trans } \\
\text { formación b/ } \\
\text { (pesos por se } \\
\text { mana) }\end{array}$ & $\begin{array}{l}\text { Sala- } \\
\text { rlos } \\
\text { reales }\end{array}$ & $\begin{array}{l}\text { Indlce } \\
\text { del PNB } \\
\text { por per- } \\
\text { sona en- } \\
\text { pleada } \\
\quad c /\end{array}$ & $\begin{array}{l}\text { Costo de } \\
\text { la mano } \\
\text { de obra } \\
\text { por uni- } \\
\text { dad de } \\
\text { produe- } \\
\text { clón }\end{array}$ \\
\hline $\begin{array}{l}1945 \\
1950 \\
1955 \\
1960\end{array}$ & $\begin{array}{l}100.0 \\
167.0 \\
257.2 \\
341.9\end{array}$ & $\begin{array}{r}46.94 \\
81.07 \\
126.88 \\
197.07\end{array}$ & $\begin{array}{r}100.0 \\
90.6 \\
100.0 \\
123.0\end{array}$ & $\begin{array}{l}100 \\
124 \\
143 \\
164\end{array}$ & $\begin{array}{l}100.0 \\
73 \\
7 \quad 70 \\
74.5\end{array}$ \\
\hline
\end{tabular}

astimacion para 6 ciudades industriales, por M. Everett, The Evolution of the Mexican Wage Structure, El Colegio de México, inédito.

b M. Everett, lac. cit., promedio de los salarios semanales en 33 ramas industriales en 6 ciudades.

c Calculado con datos de Nacional Financiera, La economía mexicana en cifras, México, p. 52.

11 El cálculo anterior (véase también el cuadro 3) sobrestima la baja de los salarios reales, puesto que el índice de los salarios nominales no toma en cuenta las diferencias de salarios por diferencias de calificación ante la creciente de- 
Un largo período con producto creciente por hombre ocupado, aunado a salarios reales decrecientes o constantes, implica una redistribución del ingreso en la sociedad. El trabajador industrial mexicano, al aceptar un salario real en el mejor de los casos estático, parece haber contribuido notablemente al financiamiento del proceso de inversión y desarrollo. Bien puede decirse que no se han presentado aumentos autónomos de los salarios por encima de los aumentos de la productividad. En consecuencia, la inflación de costos de mano de obra debe rechazarse como una explicación del alza de los precios en México. Por el contrario, los asalariados han tenido una influencia estabilizadora y pueden haber impedido que la inflación se convirtiera en una espiral acumulativa.

Por otra parte, los salarios pudieron haber desempeñado un papel trasmisor en el proceso inflacionario. Éste puede haber sido el caso si los incrementos anuales de los salarios medios, aunque menores que los aumentos de precios, se hubieran anticipado a éstos; sin embargo, la disminución de los costos de la mano de obra debe haber impuesto un freno a la inflación.

\section{Salarios e inversión}

¿Provocó la reducción de los costos de la mano de obra un aumento de las utilidades y de la inversión?

Supongamos que la inversión es función de las utilidades:

$$
\begin{aligned}
& I=f(P) \\
P= & \text { utilidades } \\
\pi= & \text { nivel de precios } \\
c= & \text { costos } \\
w= & \text { costos de la mano de obra } \\
m= & \text { costos de las materias primas y de } \\
& \text { los bienes intermedios } \\
k= & \text { costo del capital }
\end{aligned}
$$

en que

$$
\begin{aligned}
& P=\pi-c \\
& c=w+m+k \\
& P=\pi-(w+m+k)
\end{aligned}
$$

Consideremos la evolución de $m \mathrm{y}$ de $k$ :

Aunque el costo de $m$ ha aumentado continuamente, el aumento de los precios de uso final ha sido siempre mayor que el de $m .^{12}$ Por lo tanto, el efecto neto de estos dos movimientos ha sido un aumento de las utilidades.

La tasa de interés no ha variado significativamente durante el período. Las variaciones en la disponibilidad de crédito han sido el méto-

manda y, por lo tanto, no le da el peso debido a los cambios en la estructura del empleo.

12 Cálculo basado en los índices de precios al mayoreo de los informes anuales del Banco de México. 
do principal de control. Para nuestro propósito, es razonable suponer que el costo del capital es una constante.

Un breve análisis de $P=\pi-(w+m+k)$ lleva a la conclusión de que hubo un aumento en las utilidades debido a una reducción significativa del costo de los insumos de mano de obra a los precios relativos más altos de los bienes de consumo que de los bienes de producción a lo largo del período.

El supuesto de un aumento en la participación de las utilidades en el producto bruto que hemos establecido encuentra confirmación en la distribución del ingreso personal. Es también congruente con los cambios en la distribución factorial del ingreso. (Véase el cuadro 5.)

\section{Cuadro 5}

MÉXico: Distribución factorial del producto bRUto INTERNo

(En porcientos)

\begin{tabular}{lrrrr}
\hline & 1940 & 1950 & 1960 & 1966 \\
\hline Producto bruto interno & 100.0 & 100.0 & 100.0 & 100.0 \\
Salarios y sueldos & 29.1 & 23.8 & 28.7 & 26.3 \\
Remuneración a propietarios que & & & & \\
trabajan & 7.2 & 5.1 & 7.0 & 6.2 \\
Renta e intereses & 8.1 & 6.0 & 7.5 & 7.1 \\
Ingresos mixtos & 27.3 & 23.9 & 27.0 & 25.8 \\
Utilidades & 28.6 & 41.4 & 30.1 & 34.8 \\
Corrección por impuestos indirectos & -0.3 & -0.2 & -0.3 & -0.2 \\
& & & & \\
\hline
\end{tabular}

Fuente: 1940 y 1950, Comisión Mixta, El desarrollo económico de México y su capacidad para absorber capital del exterior, México, 1953, cuadro 4, p. 18; 1960, estimación de la Junta de Gobierno de Organismos Descentralizados, Secretaría del Patrimonio Nacional, en Revista Transformación, febrero de 1964; 1966, Banco Nacional de México, Examen de la situación económica, julio de 1967.

¿Sirvió la reducción de los costos de la mano de obra y el aumento en las utilidades para llegar a financiar un volumen mayor de inversión?

Si calculamos la correlación entre salarios reales en la industria y la formación bruta interna de capital expresada como porciento del producto bruto interno tenemos los siguientes resultados: 1939-1953, $r=-.6977 ; 1954-1963, r=-.2216$, mientras la correlación entre el ahorro privado y los salarios reales es de -.2 ; ninguno de los resultados es significativo. Esto puede interpretarse en el sentido de que la participación de los salarios en los costos de las empresas es suficientemente pequeña, de tal modo que una reducción de $30 \%$ en los costos de la mano de obra no tiene gran repercusión sobre el nivel de utilidades. En forma alternativa puede pensarse que aunque las utilidades aumentaran, el aumento no significó una mayor formación de capital sino sólo niveles más altos de consumo de parte de los empresarios. Las estimaciones de la distribución del ingreso hacen improbable la primera hipótesis. (Véase el cuadro 6.) Por lo tanto, la 
segunda parecería la respuesta a nuestra pregunta. El resultado tiene cierta importancia ya que significaria que aunque ha habido ahorro forzado en México no se ha utilizado para financiar el desarrollo sino predominantemente para financiar el mayor consumo de los estratos de ingreso superiores.

\section{Cuadro 6}

MÉxico: Distribuctón DEL INGReso FAMILIAR, 1950 y 1957

\begin{tabular}{ccc}
\hline \multirow{2}{*}{$\begin{array}{c}\text { Mímero de familias } \\
\text { (deciles) }\end{array}$} & \multicolumn{2}{c}{ Porciento del } \\
\cline { 2 - 3 } & 1950 & 1957 \\
\hline 1 & 2.7 & 1.7 \\
2 & 3.4 & 2.7 \\
3 & 3.3 & 3.1 \\
4 & 4.4 & 3.8 \\
5 & 4.8 & 4.3 \\
6 & 5.5 & 5.6 \\
7 & 7.0 & 7.4 \\
8 & 8.6 & 10.2 \\
9 & 10.8 & 14.7 \\
10 & 49.0 & 46.7 \\
\hline
\end{tabular}

Fuente: Ifigenia M. de Navarrete, La distribución del ingreso $y$ el desarrollo económico de México, México, 1960, tomado del cuadro 12, p. 85.

\section{CONSIDERACIONES ESTRUCTURALES}

Los economistas "estructuralistas" consideran que la inflación es consecuencia de estrangulamientos que surgen en el proceso de desarrollo cuanto estructuras inelásticas de oferta necesitan ajustarse a cambios sustanciales en el nivel de la demanda.

En México, una serie de políticas gubernamentales ha dado a la economía una flexibilidad sustancial. Los programas de reforma agraria acompañados por programas de irrigación y servicios de extensión, la expansión de la red de transportes y comunicaciones, el suministro adecuado de energía y combustibles y la inversión en educación y en salubridad comenzaron en México mucho antes de la segunda Guerra Mundial. Desde 1940 el desarrollo industrial se ha estimulado también mediante protección arancelaria, incentivos fiscales $\mathrm{y}$, recientemente, el fomento de la inversión industrial por la Nacional Financiera.

Como resultado de estas políticas, la economía mexicana de 1966 no muestra estrangulamientos ni desequilibrios estructurales y presenta una diversificación mucho mayor que en 1945. Observemos con mayor detalle los dos estrangulamientos que más frecuentemente mencionan los escritores estructuralistas, o sea aquellos que surgen de una oferta inelástica de alimentos y de una escasez de divisas. 


\section{La demanda y la oferta de alimentos}

Se considera en forma generalizada que la demanda de alimentos en un país es función de la tasa de crecimiento de la población y de la elevación del ingreso per capita. Si la tasa de crecimiento de la oferta de alimentos en una "economía cerrada" fuera menor que la de la demanda de alimentos, la relación interna de precios del intercambio se movería contra los trabajadores no-agrícolas con el descontento resultante de la mano de obra industrial y la renuencia de la mano de obra a desplazarse de la agricultura, obstaculizando así el desarrollo de la industria. Por lo tanto, el comportamiento del sector agrícola tendrá un efecto decisivo sobre la capacidad de un país para mantener la estabilidad interna conforme la economía se desarrolle.

El uso de datos de las encuestas sobre gastos familiares en un momento dado para estimar la elasticidad-ingreso de la demanda de alimentos presenta dificultades cuando los ingresos cambian rápidamente, ya que la población no cambia su patrón de consumo de inmediato en respuesta a cambios del ingreso. En especial, el consumo "permanente" a largo plazo puede subestimarse. ${ }^{13}$ Goreux ha estimado la elasticidad-ingreso de la demanda de alimentos en diversas partes del mundo como sigue: ${ }^{14}$

$\begin{array}{ll}\text { Asia y Lejano Oriente (excepto Japón) } & 0.9 \\ \text { Medio Oriente y Africa (excepto Sudáfrica) } & 0.7 \\ \text { América Latina (excepto Argentina y Uruguay) } & 0.6 \\ \text { Japón } & 0.6 \\ \text { Europa mediterránea } & 0.55 \\ \text { Comunidad Económica Europea } & 0.5 \\ \text { Resto de Europa Occidental } & 0.2 \\ \text { América del Norte } & 0.16\end{array}$

Más específicamente, la CEPAL estimó para México una elasticidadingreso de la demanda de alimentos de 0.5 , basándose en el consumo aparente de 1945-1946 a $1955 .{ }^{15}$ Un estudio más reciente de las autoridades mexicanas deriva de series temporales una elasticidad de 0.66 para productos agrícolas en 1950 , y de 0.56 en 1960 , y de una nueva encuesta sobre ingresos y gastos familiares obtiene una elasticidad de 0.35 en 1963.16

Usando estimaciones diferentes de la elasticidad-ingreso total de la demanda de alimentos, su comparación con la tasa de crecimiento de la oferta de alimentos muestra lo siguiente:

13 M. Friedman, A Theory of the Consumption Function, Princeton, 1954.

14 L. M. Goreux, "Ingreso y consumento de alimentos", Boletin Mensual de Economia y Estadística Agrícola, Vol. IX, Núm. 10, FAO, Roma, octubre de 1960.

15 CEPAL, El desequilibrio externo en el desarrollo económico latinoamericano: el caso de México, Parte II, p. 135, Doc. E/CN.12/428, 1957, mimeografiado.

16 Secretaría de Agricultura y Ganadería, Secretaría de Hacienda y Crédito Público y Banco de México, Proyecciones de la oferta y la demanda de productos agropecuarios en México a 1965, 1970 y 1975, México, Banco de México, 1966, cuadro II-3, p. 54. 


\section{Cuadro 7}

México: Tasas de incremento DE La DEManda Y La PRODUCción DE ALIMENTOS, 1945/46 A 1965/66

\begin{tabular}{ccccc}
\hline \multirow{2}{*}{ Periodo } & \multicolumn{2}{c}{ Elasticidad-ingreso de la demanda de alimentos } & $\begin{array}{c}\text { Producción } \\
\text { de alimentos a }\end{array}$ \\
\cline { 2 - 4 } $1945 / 46-1950 / 51$ & .6 & .5 & 8.16 \\
$1950 / 51-1955 / 56$ & 4.78 & 4.45 & 7.75 \\
$1955 / 56-1960 / 61$ & 4.9 & 4.6 & 5.19 \\
$1960 / 61-1965 / 66$ & 4.9 & 4.6 & 6.88 \\
\hline
\end{tabular}

a Basada en un indice de quantum de las siguientes cosechas alimenticias: trigo, maíz, frijol, papa, arroz, jitomate, naranja, plátano, manzana y pera, caña de azúcar, chile, semilla de algodón y café. Las carnes de res y de cerdo se incluyen sólo en el período 1950-1965, ya que no hay datos disponibles para los años anteriores. Los datos șobre las cosechas se obtuvieron de la Oficina de Estudios sobre Proyecciones Agrícolas, Banco de México. Los datos de carnes de res y de cerdo se obtuvieron de la Dirección General de Estadística. Parte de la oferta de alimentos se exportó (especialmente café, azúcar, jitomate y carne de res).

La comparación de las tasas de crecimiento de la oferta y la demanda de alimentos indica que, durante los cuatro períodos, la oferta creció más rápidamente que la demanda. Por lo tanto, es razonable suponer que desde la guerra el aumento medio de la oferta de alimentos fue suficiente para evitar que los alimentos fueran un obstáculo y un origen de presión alcista de los precios.

Esta conclusión general se mantiene para cada una de las cosechas que forman la base de la dieta del mexicano y su fuente principal de calorías : maíz, frijol y trigo.

\section{Sustitución de importaciones}

Desde la segunda Guerra Mundial el crecimiento de las exportaciones mexicanas se ha rezagado respecto al del producto bruto. Sin embargo, la vecindad con Estados Unidos ha permitido a México desarrollar una importante industria turística y un sustancial comercio fronterizo que han contribuido en forma creciente a la capacidad para importar, especialmente en el período 1955-1960, que fue de estancamiento de las exportaciones de mercancías. Mientras que en 1950 el $66 \%$ de la capacidad para importar de México fue generado por las exportaciones de mercancías, en 1965 sólo lo fue el $58 \%$, explicándose el resto por el turismo y las transacciones fronterizas. Pero, de cualquier manera, de 1950 a 1966 la capacidad para importar aumentó a una tasa anual de sólo $3.1 \% .17$

Por lo tanto, a pesar de la contribución hecha por el turismo, la capacidad para importar de México ha crecido más lentamente que el producto bruto. En consecuencia, las importaciones han crecido más lentamente que éste y exceptuando el efecto del financiamiento a largo plazo, se ha llevado a cabo suśtitución de importaciones. La participación de las importaciones en el producto bruto ha disminuido de $15 \%$ en 1945-1948 a $9.6 \%$ en 1961-1965.

17 Calculada con datos de la CEPAL, diversas publicaciones. 
Por otra parte, la elasticidad-ingreso de la demanda de importaciones tiende a ser mayor que uno, siempre que la tasa de crecimiento del producto bruto sea mayor que $2 \% .{ }^{18}$ Por lo tanto, al aumentar la tasa de crecimiento, aun cuando la causa de la aceleración sea la demanda externa de productos mexicanos, la capacidad para importar de la economía puede rezagarse respecto a la tasa "requerida" de crecimiento de las importaciones, dando lugar a desequilibrios de la balanza de pagos. Cuando el crecimiento de la economía es generado por factores internos y no inducido por exportaciones crecientes, la presión de la demanda de importaciones creará desequilibrios graves de la balanza de pagos. La necesidad de restringir las importaciones al nivel permitido por las divisas constantes del país plantea en última instancia la alternativa de prescindir de algunos de los bienes importados o de producirlos internamente. La solución ha sido a medias: ciertas importaciones (principalmente bienes de consumo) se reemplazan por producción interna, mientras otras (bienes de capital) continúan importándose en vez de producirse localmente. La rápida industrialización de México data de los años cuarenta y su iniciación fue en gran parte consecuencia de la segunda Guerra Mundial. Sin embargo, ya antes de ésta existían industrias productoras de alimentos y de otros bienes de consumo. Varios productos intermedios que requieren importantes inversiones en planta y equipo, tales como hierro y acero, cemento, vidrio, hule y papel ya se producían internamente aunque no en cantidad suficiente para satisfacer la demanda. El proceso de sustitución de importaciones descansó en los años de posguerra en una política de restricción de las importaciones.

La producción industrial se duplicó durante los años cincuenta. Su crecimiento se aceleró en la segunda mitad del decenio cuando México experimentó una notable reducción en la capacidad para importar medida como proporción del producto bruto. Durante 19501964, la tasa de crecimiento anual del valor agregado por la industria manufacturera varió de $3.9 \%$ en textiles a 5-10\% en madera y corcho, alimentos, bebidas y tabaco, imprenta y editorial, papel y celulosa, productos minerales no metálicos, productos químicos e industrias diversas; a 11-14\% en vestido y calzado, equipo de transporte, artículos de cuero (excepto calzado) y manufacturas de hierro y acero y metales, y hasta $19 \%$ en la producción de maquinaria..$^{19}$

El simple listado de las diferentes industrias de acuerdo a su tasa de crecimiento indica sustitución de importaciones. Las industrias que crecieron más rápidamente fueron aquellas cuyos productos suelen ser importados por los países subdesarrollados: maquinaria, hierro $\mathrm{y}$ acero, productos químicos, etc.; mientras que las ramas que han crecido menos que el promedio son industrias que por su naturaleza se establecen más fácilmente y que, como la textil, han estado produciendo durante largo tiempo.

$\mathrm{Al}$ estar las importaciones sujetas a permisos de importación y aranceles, las industrias que sustituyen importaciones pueden crecer

18 Se estimó que la elasticidad-ingreso tendía a 1.69 mientras la tasa de crecimiento aumentara. Véase CEPAL, El caso de México, op. cit., pp. 79-80.

19 El desarrollo industrial de México, trabajo presentado por el gobierno mexicano al Simposio Industrial de América Latina, Santiago de Chile, 1966. 
a una tasa más rápida que aquella a la que crece su mercado, al menos por algunos años, al penetrar en la parte del mercado que antes era cubierto por las importaciones. Las industrias antes establecidas, por otra parte, dependen para su crecimiento del crecimiento del mercado interno.

\section{Proteccionismo}

Los impuestos a la importación en 1960, calculados a base de las tasas nominales sobre los precios oficiales de importación (frecuentemente más altos que los precios c.i.f. reales), varían desde menos de $10 \%$ en combustibles minerales, materias primas excepto combustibles y maquinaria no eléctrica (grupos (SITC 32 y 71), a, por ejemplo, de 10 a $20 \%$, en alimentos de origen animal, elementos y compuestos químicos, maderas y corcho, y manufacturas de metales no ferrosos (grupos SITC 0, 5, 63, 68), hasta 20 a $50 \%$ en aceites y grasas vegetales y animales, manufacturas básicas y manufacturas diversas (grupos 4,5 y 8 ). Son comunes tasas tan altas como $67 \%$ sobre textiles (grupo 65 ) y $140 \%$ sobre bebidas y tabaco (grupo 1), y aun tasas mayores en muchos artículos individuales. ${ }^{20} \mathrm{La}$ "protección efectiva" calculada sobre el valor agregado es en México generalmente mayor para productos manufacturados y menor para mercancías primarias. ${ }^{21}$,

La protección ha sido otorgada por el simple criterio de considerar a todas las industrias establecidas en el país como benéficas para el desarrollo de la economía, y por lo tanto con derecho a protección. No es necesario subrayar que a muchas firmas ineficientes y mal planeadas se les ha dado un mercado cautivo en el cual pueden sobrevivir a pesar de sus altos precios o de la mala calidad de sus productos.

De la misma manera, la protección ha convertido a varias empresas en monopolios al eliminar del mercado a sus únicos competidores: los productores extranjeros. En resumen, la política mexicana de protección ha sido indiscriminada al proteger a todos sin consideración del tamaño y eficiencia de los productores, de los efectos de la protección sobre el bienestar de la comunidad, de sus efectos sobre la distribución del ingreso o de las prácticas monopólicas que pueden derivarse de ello. Las condiciones monopólicas en la industria ejercen una especie de "efecto trinquete" (ratchet effect) sobre los precios al permitir que éstos se eleven en ciertas condiciones, pero haciendo mucho más improbable su reducción en períodos de oferta excesiva.

Es claro que aún si la oferta monetaria y la velocidad de circulación se mantienen pasivas, el resultado de una reducción en la demanda de los bienes que no tienen un precio monopólico elevará los precios relativos de aquellos bienes para los cuales la demanda se ha incrementado, ${ }^{22}$ lo cual no se compensará por una caída de los precios relativos en los sectores monopólicos que producen los bienes primarios. El resultado de este proceso da un sesgo ascendente al nivel general de los precios.

20 Gerardo M. Bueno, La estructura de la protección efectiva en México en 1960, inédito.

21 Ibid.

222 Excepto cuando la estructura de la oferta puede ajustarse a un cambio en la demanda con costos marginales constantes. 
Aunque con relación a otros países en vías de desarrollo las distorsiones pueden parecer pequeñas, ya que México ha mantenido un tipo de cambio realista y costos moderados de los factores, prevalecen condiciones oligopólicas en la mayoría de las industrias mexicanas. Las industrias automotriz, de llantas y caucho, hierro y acero, productos eléctricos, químicos, farmacéuticos y medicinales, papel, maquinaria, tabaco, cerveza, vidrio, cemento, jabón y detergentes, cosméticos, alimentos enlatados, galletas, aceites y grasas alimenticias, son algunos ejemplos. Este medio ambiente lleva a la presunción de que las presiones alcistas de los costos resultantes del costo creciente de los insumos importados, los salarios nominales más altos $u$ otros incrementos del costo tienden a producir incrementos "administrados" en los precios de las manufacturas.

\section{CONCLUSIÓN}

Volviendo, a manera de conclusión, a la pregunta planteada por este documento, la fuente principal de las presiones inflacionarias sobre el nivel de precios de México parece haber sido el exceso de demanda. La evidencia sobre "inflación de costos" y, en menor grado, sobre desequilibrios estructurales, es esencialmente negativa. ${ }^{23}$

Mientras que durante el decenio de inflación, el proceso de desarrollo y de sustitución de importaciones se llevaban a cabo, los precios se incrementaron en forma cíclica que correspondió estrechamente al influjo de la demanda. Desde los últimos años del pasado decenio se siguieron políticas monetarias más conservadoras. El rápido crecimiento del mercado de valores estimulado por estas políticas, conjuntamente con la utilización creciente de los créditos externos, ha permitido el financiamiento de inversiones sustanciales sin recurrir a la expansión monetaria.

23 EI estancamiento de las exportaciones en los años 1955-1960 puede considerarse como un estrangulamiento que pudo haber resultado en presiones inflacionarias si no hubiera recurrido el gobierno a créditos del exterior. La tasa de crecimiento de la producción industrial no fue más rápida en esos años que en los que siguieron. 